Research Article

\title{
Subway Tunnel Construction Settlement Analysis Based on the Combination of Numerical Simulation and Neural Network
}

\author{
Qiangqiang Ma $\mathbb{D}$, Wentao Li, and Yongjun Zhang $(\mathbb{D}$ \\ Qingdao University of Technology, Qingdao 266033, Shandong, China \\ Correspondence should be addressed to Qiangqiang Ma; 230218294@seu.edu.cn
}

Received 20 July 2021; Revised 26 August 2021; Accepted 7 September 2021; Published 28 October 2021

Academic Editor: Bai Yuan Ding

Copyright (c) 2021 Qiangqiang Ma et al. This is an open access article distributed under the Creative Commons Attribution License, which permits unrestricted use, distribution, and reproduction in any medium, provided the original work is properly cited.

\begin{abstract}
Under the background of rapid economic development and the continuous expansion of city size, people's travel is deeply troubled by the problem of urban traffic congestion. Subway is an effective way to relieve traffic pressure and plays an important role in its use. In the process of building the city subway, the excavation of the underground tunnel is the most critical. However, the excavation of the tunnel will inevitably disturb the nearby soil, change the stratum stress conditions, and make the stress distribution uneven. If the surface settlement is too large, it will not only affect the normal construction of the tunnel but also cause damage to the surrounding buildings (structures), roads, underground pipelines, and so on, resulting in very serious malignant consequences. In this study, Cuobuling Station is taken as a case study. First, the construction status of the subway tunnel in the station is analyzed, and then the monitoring results are analyzed. According to the cross-section settlement law, the numerical simulation and neural network are used to build a model, calculate the numerical simulation results, and carry out a risk assessment of regression model. Finally, combined with the tunnel construction situation of the station, according to the risk assessment results, the concrete measures are put forward to deal with the subway tunnel construction settlement problem.
\end{abstract}

\section{Introduction}

As an effective way to relieve traffic pressure, the subway plays an important role. It is foreseeable that the construction of urban subways in the future will usher in new development opportunities. The well-developed shield construction will still disturb the soil layer, and different levels of ground displacement and surface subsidence will occur [1]. Once this phenomenon exceeds a certain range, the safety of adjacent buildings and underground pipelines will not be guaranteed, and geotechnical environmental engineering problems will be caused one after another [2]. In order to reduce the disturbance of surrounding soil and reduce the adverse impact on adjacent buildings (structures), many experts and scholars are committed to finding a method to control surface settlement to a great extent [3]. Therefore, it is very important to study the evolution law and control method of surface subsidence, which is one of the most critical research issues $[4,5]$. Based on the Cuobuling
Station project of Qingdao Metro Line 4, the evolution law of ground subsidence caused by subway shield construction was analyzed and studied in this paper. And a series of measures are summarized to control the ground subsidence, so as to ensure the safety of Qingdao metro shield construction, but also to provide a reference for the ground subsidence caused by the construction of similar areas in the future.

\section{Project Summary}

Cuobuling Station is a nine-seat station of Qingdao Metro Line 4, which interchanges with the Cuobuling Station of Line 3. The strata involved in the temporary construction of the shaft and the cross passage are mainly the artificial filling soil of the Quaternary-Holocene, alluvial and diluvial deposits of the Quaternary Holocene, and late Yanshanian granite. Controlled by the Cathaysia tectonic system, the regional main tectonic trajectory in the Qingdao area is a 
group of NE-trending faults distributed diagonally, with the characteristics of high inclination, overall inclination to the northwest, and local counterinclination. From west to east, there are the Cangkou fault, the Pishikou-Fushan fault, and the Wanggezhuang-Shandongtou fault. The main types of groundwater in the field are Quaternary pore water and bedrock fissure water. The Quaternary pore water mainly occurs in the filling soil and the ninth layer of coarse sand, which is rich in water and belongs to medium to strong permeable layer. The bedrock fissure water occurs in layers and bands in the strong wind zone of the bedrock and the densely developed zone of fissures. Due to the uneven development of fissures, its water richness is uneven.

\section{Monitoring Results}

3.1. Testing Arrangement. In Cuobuling Station, a total of seven survey lines are arranged on the road surface, including five-line survey and two-point survey. The surface detection line layout diagram is shown in Figure 1:

Within the detection range, the electromagnetic wave is distributed regionally, and the distribution uniformity of the energy group is poor. There are obvious diffraction and refraction phenomena in the local electromagnetic wave. There is a fault in the in-phase axis, and the reflected wave energy in local areas is strong, and the amplitude is high. In view of the complex structure of the overlying soil layer and numerous pipelines under the road surface, there is a great interference to the identification of radar Atlas. It is expected that the local area rock strata are broken, and there are weak structures and bedding structural planes. Surface detection results map is shown in Figure 2.

3.2. Cross-Section Settlement Law. Three sections are selected, and five groups of monitoring data are taken from each section [6]. During the whole process of the shield machine passing through each section (including before, during, and after the shield machine passing through), the field surface subsidence monitoring is carried out. Because the number of rings advanced by the shield machine is different in different monitoring periods, the interpolation method is adopted locally for data processing when the monitoring data is counted.

3.3. Analysis Method. With the development of computer technology, numerical analysis methods have been realized; the application of numerical analysis methods in geotechnical engineering began in the 1960s [7], among which the most widely used methods are the finite element method (FEM) and finite difference method (FDM).

3.3.1. Finite Element Method (FEM). The finite element method establishes the relationship between force and displacement based on the basic mechanics principle of continuum and calculates the displacement and stress of unknown nodes according to the known stress and strain of each division element [8].

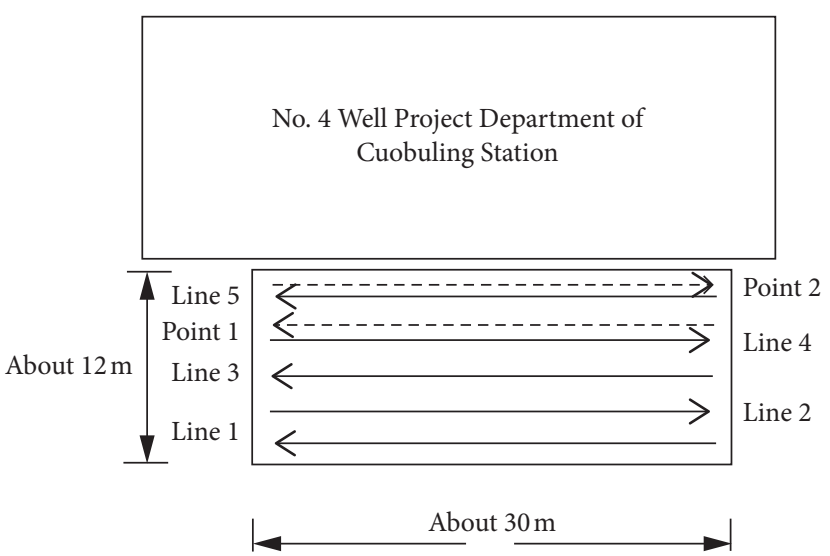

FIgURE 1: Surface detection line layout diagram.

3.3.2. Finite Difference Method (FDM). The solution of a given initial and boundary value problem is the finite difference method, an earlier numerical analysis method. With the rapid development of computer technology, the finite difference method has shown certain advantages in the numerical analysis due to its unique calculation format and calculation flow [9].

3.4. Numerical Simulation Software. At present, the common numerical analysis software includes ANSYS, MIDAS/ GTS, ABAQUS, PLAXIS, and so on. Different numerical simulation software have their own advantages and disadvantages and are suitable for different research fields.

In the civil construction industry, ANSYS simulation software can accurately deal with and simulate the situation of stressed nodes. Because of its own characteristics, ANSYS software can be used for physical simulation analysis in many disciplines, such as fluid mechanics, geotechnical engineering, structural engineering, and other disciplines.

The MIDAS/GTS provides a reference for the research and calculation of underground engineering. It has advanced representation, and it can provide good solutions in tunnel construction or other more complex environments [10]. The ABAQUS is not only well used in simple linear domain simulations, but also for relatively difficult nonlinear simulations. The simulation in the linear domain can also be solved a lot.

In this paper, PLAXIS 3D numerical analysis software is used to carry out numerical simulations of the shield construction process. Now the PLAXIS software is briefly introduced, with emphasis on its calculation and analysis function and modeling process. PLAXIS has powerful calculation and analysis functions, stable calculation, and accurate results [11]. The software CCP includes three modules: main module, seepage module, and dynamic module, which can perform numerical analysis of various conditions such as consolidation, fluid-solid coupling, plasticity, and dynamics.

\section{Model Building}

4.1. Shield Excavation Model. The lining of shield tunnels is usually composed of precast concrete segments, and the precast concrete segments are connected by bolts during 


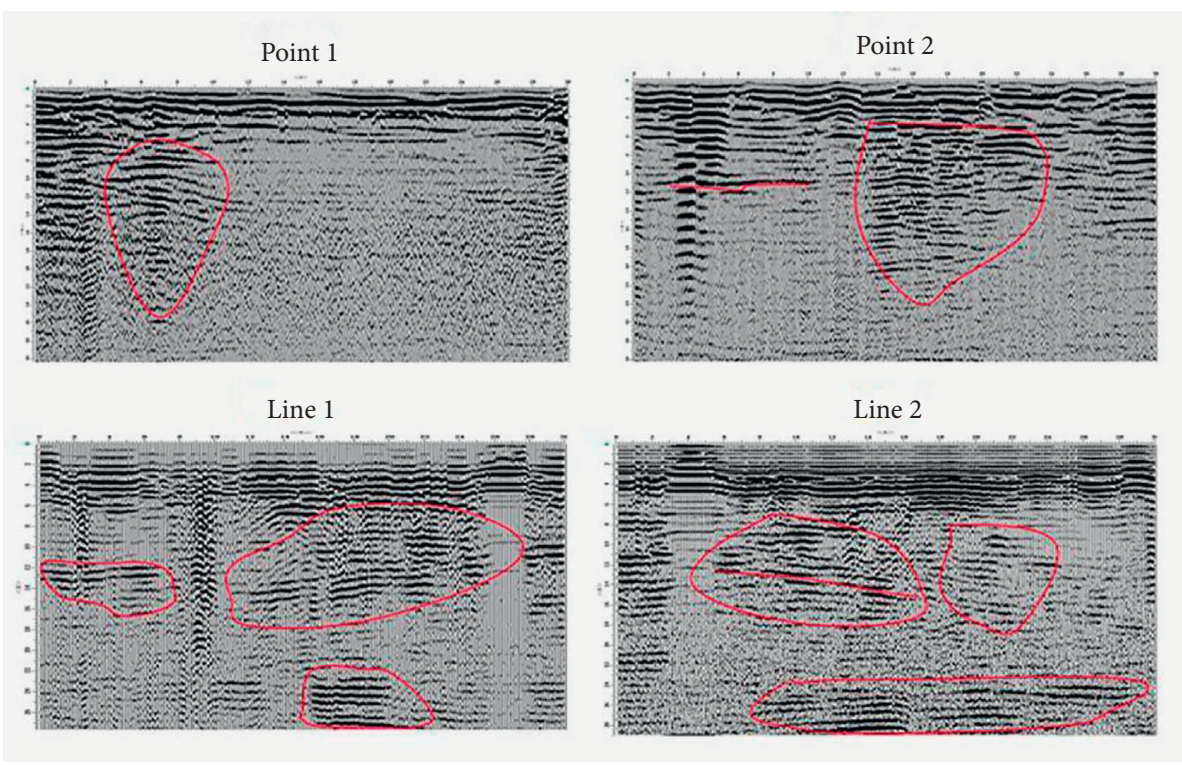

Figure 2: Surface detection results map.

shield tunneling to form the tunnel lining [12]. The simulated construction process is divided into several construction stages according to the length of each ring lining segment, which is generally about $1.5 \mathrm{~m}$ long. Considering that the overlaying soil layer above the tunnel is different at different sections, numerical simulation analysis is carried out on the three selected representative sections to calculate the settlement results. The detailed modeling process is as follows.

4.1.1. Geometric Model Building and Parameter Input. Shield construction is mainly a construction method in which the shield machine is used as a tunnel excavation tool. In order to prevent the collapse of the tunnel surrounding the rock, the shield machine is pushed forward while laying tiles and lining. Before excavation, the soil is excavated with a cutting device. The excavated machine is out of the hole, the jack is pressed on the top, and precast concrete segments are assembled to form a tunnel structure. In the numerical simulation of the tunnel excavation construction process, the project is often simplified appropriately. According to the geological investigation data and the study of boundary conditions, two adjacent borehole intervals are selected as the study area of the geometric model [13]. The length of the model is $80 \mathrm{~m}$ (in the direction of the $X$ axis); the width is $20 \mathrm{~m}$ (in the direction of the $Y$-axis); and the thickness is $30 \mathrm{~m}$ (in the direction of the $Z$-axis). The buried depth of the tunnel is $18 \mathrm{~m}$; the outer diameter of the shield is $6.3 \mathrm{~m}$; the inner diameter of the shield is $5.7 \mathrm{~m}$; each segment ring is $1.5 \mathrm{~m}$; and the wall thickness is $0.3 \mathrm{~m}$. The physical and mechanical parameters such as cohesion, friction angle, elastic modulus, and Poisson's ratio of the overburden soil layer are simulated by solid elements. Reference table of section soil material is shown in Table 1.

Model plate unit material properties are shown in Table 2.

Numerical simulation of three-dimensional model meshing is shown in Figure 3.
4.1.2. Defining Structural Units and Creating Advanced Excavation Segments. Shield excavation, support, and other relevant contents are defined under the "structural mode," and the tunnel shield machine (TBM) is used to carry out the excavation [14]. The length of the shield is $9 \mathrm{~m}$, and the diameter is $6.3 \mathrm{~m}$. The tunnel inner and outer diameter profile is established, and the inner and outer diameter profile surface of the left half tunnel lining is established to form the left half tunnel entity. In order to simulate the shield machine's propulsion process, it is divided into five stages, including the initial position of the shield and four stages of propulsion, with each stage advancing $10 \mathrm{~m}$ and each advancing $1.5 \mathrm{~m}$, divided into seven times. The initial position of the section shield is shown in Figure 4.

(1) Creating the Tunnel Face to Balance the Pressure and Jack Thrust. The equilibrium pressure of the tunnel face is bentonite pressure, which increases linearly with depth. At the same time, in the process of tunnel excavation, the shield needs to push itself forward and separate from the completed lining. This process is realized by hydraulic jacks. Therefore, the force exerted by the jacks on the tunnel lining should be considered in the model.

(2) Defining Shield, Surface Shrinkage, Grouting Pressure, and Soil-Structure Interaction. The "Create Plate" of the outer cylinder of the model is selected to specify the plate element for the surface representing the shield machine. Each stage is only $9 \mathrm{~m}$ long in the active state to simulate the shield machine [15]. Once again, the "Creation Surface Shrink" of the outer cylinder is selected, and the distribution type and value of the contraction will be defined in the calculation stage. The grouting pressure was defined, and the "original surface load" of the outer cylinder was selected to simulate the grouting pressure. Finally, the interaction between soil and structure is simulated around the tunnel. 
TABLE 1: Reference table of section soil material.

\begin{tabular}{|c|c|c|c|c|c|c|c|}
\hline Tab & Parameter & Symbol & Concrete & Marl layer & Clay layer & Plain fill layer & Unit \\
\hline \multirow{4}{*}{ General } & Material model & - & Linear elasticity & Moore-Cullen & Moore-Cullen & Moore-Cullen & - \\
\hline & Drainage type & - & Nonporous & Drain & Drain & Drain & - \\
\hline & Natural severity & $\gamma_{\text {unsat }}$ & 27 & 17 & 16 & 17 & $\mathrm{kN} / \mathrm{m}^{3}$ \\
\hline & Saturation severity & $\gamma_{\text {sat }}$ & 一 & 20 & 18 & 20 & $\mathrm{kN} / \mathrm{m}^{3}$ \\
\hline \multirow{5}{*}{ Parameter } & Elastic modulus & $E_{\text {ref }}$ & $3.10 \mathrm{E} 7$ & $7.50 \mathrm{E} 4$ & $1.00 \mathrm{E} 4$ & $1.30 \mathrm{E} 4$ & $\mathrm{kN} / \mathrm{m}^{3}$ \\
\hline & Poisson’s ratio & V & - & 0.10 & 0.30 & 0.35 & 0.30 \\
\hline & Cohesion & $C^{\prime}$ & - & 35 & 15 & 10 & $\mathrm{kN} / \mathrm{m}^{3}$ \\
\hline & Friction angle & $\rho$ & - & 31 & 25 & 21 & $\left({ }^{\circ}\right)$ \\
\hline & Dilatancy angle & $\psi$ & - & 0 & 0 & 0 & $\left({ }^{\circ}\right)$ \\
\hline Interface & Interface strength & $R_{\text {inter }}$ & Rigidity & Rigidity & Rigidity & Rigidity & - \\
\hline Initial conditions & Initial horizontal stress coefficient & $K_{0}$ & Automatic & Automatic & Automatic & Automatic & - \\
\hline
\end{tabular}

TABLE 2: Model plate unit material properties.

\begin{tabular}{|c|c|c|c|c|c|}
\hline Name of the material & $\begin{array}{l}\text { Natural density }(\mathrm{g} / \\
\left.\mathrm{cm}^{3}\right)\end{array}$ & $\begin{array}{l}\text { Compression modulus } \\
(\mathrm{MPa})\end{array}$ & $\begin{array}{l}\text { Angle of internal } \\
\text { friction }\left(^{\circ}\right)\end{array}$ & $\begin{array}{l}\text { Cohesion } \\
\quad(\mathrm{kPa})\end{array}$ & $\begin{array}{l}\text { Poisson's } \\
\text { ratio }\end{array}$ \\
\hline Shield shell (70 mm thickness) & 7.72 & 210,000 & 50.00 & 20,000 & 0.28 \\
\hline $\begin{array}{l}\text { C50 concrete segment ( } 300 \mathrm{~mm} \\
\text { thickness) }\end{array}$ & 2.49 & 35,000 & 62.63 & 4,241 & 0.16 \\
\hline $\begin{array}{l}\text { Shield tail void medium (grouting } \\
\text { material) }\end{array}$ & 1.63 & 0.94 & 10.00 & 1.12 & 0.45 \\
\hline
\end{tabular}

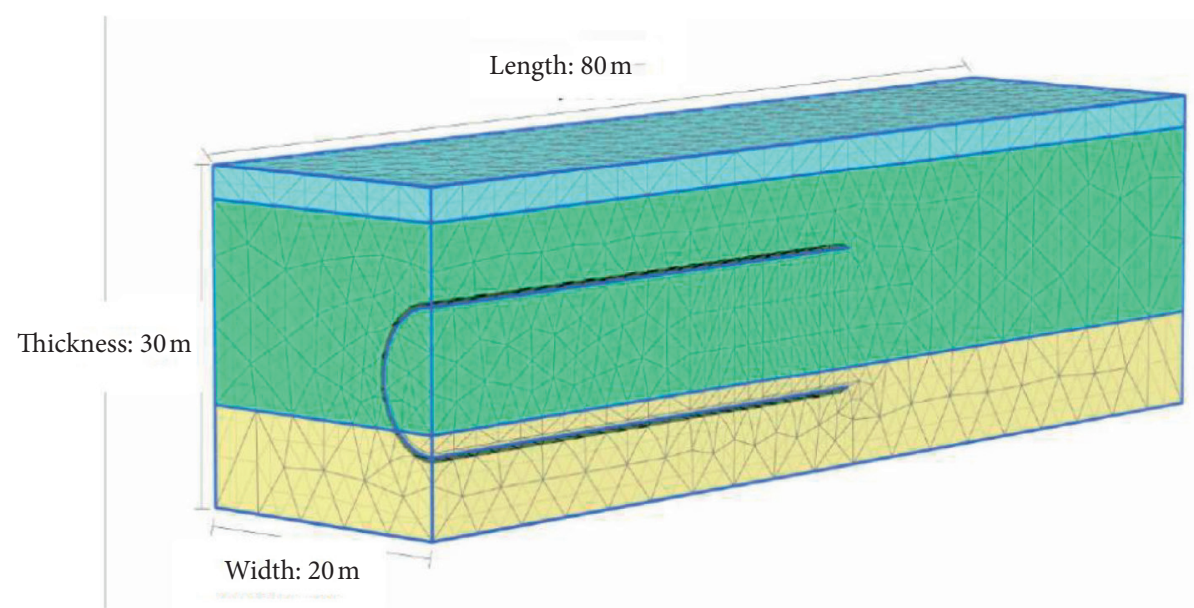

FIGURE 3: Numerical simulation of three-dimensional model meshing.

4.2. Numerical Results. The width of each ring of segments is $1.5 \mathrm{~m}$. For the convenience of numerical simulation calculation, each shield tunneling is carried out in a group of seven-ring segments with $1.5 \mathrm{~m}$ of each advance. When the distance of the shield tunneling machine from the monitoring surface is $-10 \mathrm{~m}, 0 \mathrm{~m}, 10 \mathrm{~m}, 20 \mathrm{~m}$, and $30 \mathrm{~m}$, the research and analysis are carried out. The settlement amount of the study section is counted, and the cloud map of a complete calculation stage is shown as follows.

(1) The Shield Machine Advances to a Position of - $10 \mathrm{~m}$ from the Monitoring Surface. The shield machine advances to a position of $-10 \mathrm{~m}$ from the monitoring surface, which is equivalent to the part of the soil before "freezing." The excavation releases Earth pressure, and a small amount of settlement is generated on the monitoring section. The maximum stratum uplift value is $2.814 \mathrm{~mm}$, which occurs at the grouting behind the bottom wall of the tunnel. Vertical cumulative subsidence cloud image at $-10 \mathrm{~m}$ from section YDK13+001 is shown in Figure 5.

4.2.1. Simulating Ring Wall Grouting for Excavated Soil. In the second stage, due to soil excavation, a small part of the monitoring section has subsided, so it is necessary to simulate ring wall grouting in real-time. Cloud image of ring wall grouting settlement before $-10 \mathrm{~m}$ from section YDK13+001 is shown in Figure 6.

4.2.2. Shield Machine Advances One Step Forward. A new stage is added to hide the surrounding soil of the tunnel, making it easy to select TBM, lining, surface load, and 


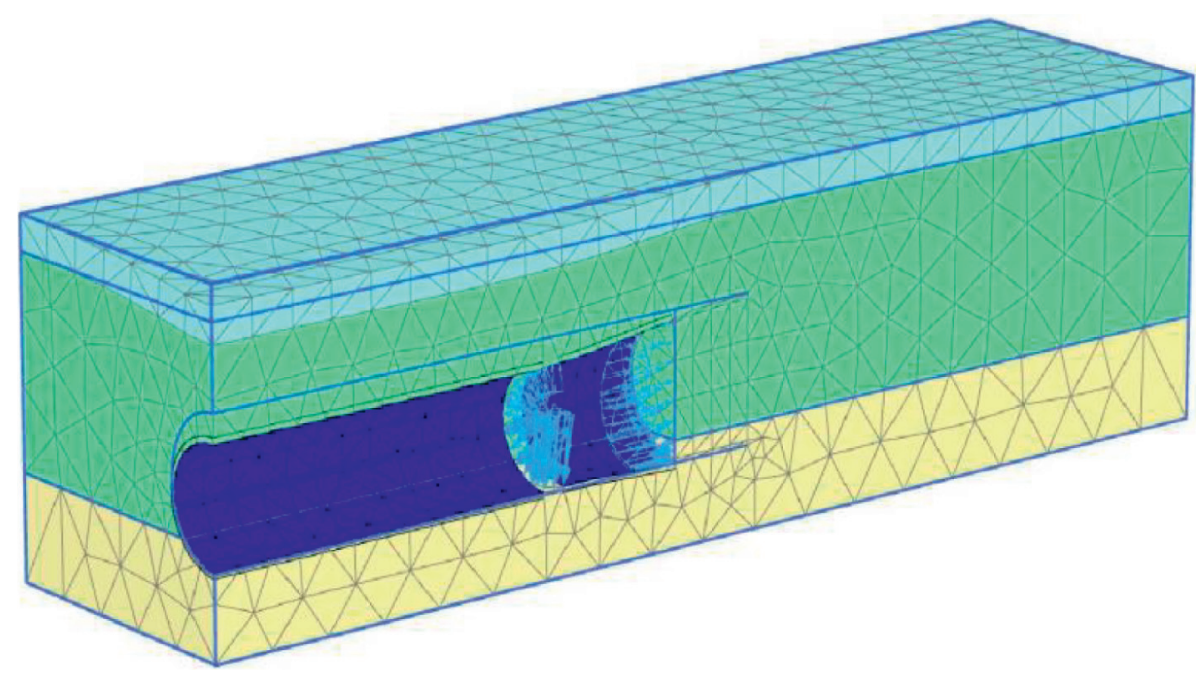

FIgURE 4: Initial position of section shield.

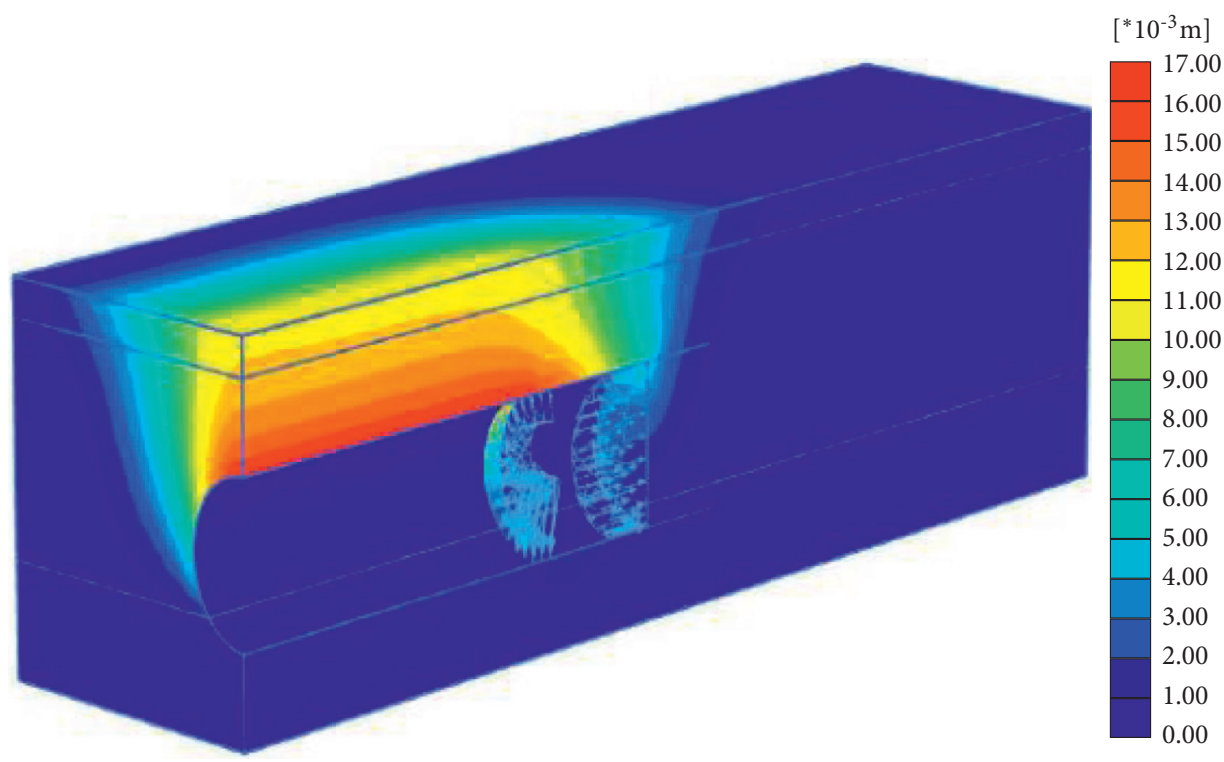

Total displacement $|\mathrm{u}|$

Maximum $=0.007 \mathrm{~m}$ (Unit 1896 is at node 1224 )

FIgURE 5: Vertical cumulative subsidence cloud image at $-10 \mathrm{~m}$ from section YDK13 +001 .

surface shrinkage from the outside and inside of the tunnel. The load between $-10 \mathrm{~m}$ and $-8.5 \mathrm{~m}$ is frozen; its forward interface is activated; and the TBM is used to advance $1.5 \mathrm{~m}$. Sedimentation cloud map at $-8.5 \mathrm{~m}$ from section YDK13+001 is shown in Figure 7 .

4.2.3. The Shield Propulsion Process from $-8.5 \mathrm{~m}$ to $-6 \mathrm{~m}$ Is Simulated. In the fourth stage, TBM was advanced from $-8.5 \mathrm{~m}$ to $-6 \mathrm{~m}$, and the simulation process is basically the same as that in the previous stage, except that the whole process is advanced along the $X$-axis by $1.5 \mathrm{~m}$. Grouting pressure from $-10 \mathrm{~m}$ to $-8.5 \mathrm{~m}$ remains unchanged; the jack thrust at $-10 \mathrm{~m}$ is removed; the grouting pressure from $-10 \mathrm{~m}$ to $-8.5 \mathrm{~m}$ needs to be changed to the lining; and the jack thrust is applied; Only $6 \mathrm{~m}-8.5 \mathrm{~m}$ is required from the tail of TBM to the grouting pressure Settlement cloud diagram at $-6.5 \mathrm{~m}$ from YDK13 +001 section is shown in Figure 8

4.2.4. The Shield Reaches the Monitoring Section. The shield machine advances cyclically, advancing forward $1.5 \mathrm{~m}$ each time, and When the TBM shield machine advances to the ydk13 + 001 section, the numerical simulation cloud diagram is shown in Figure 9.

4.3. Regression Model Risk Assessment. The artificial neural network evaluation model for large-section tunnels uses a 


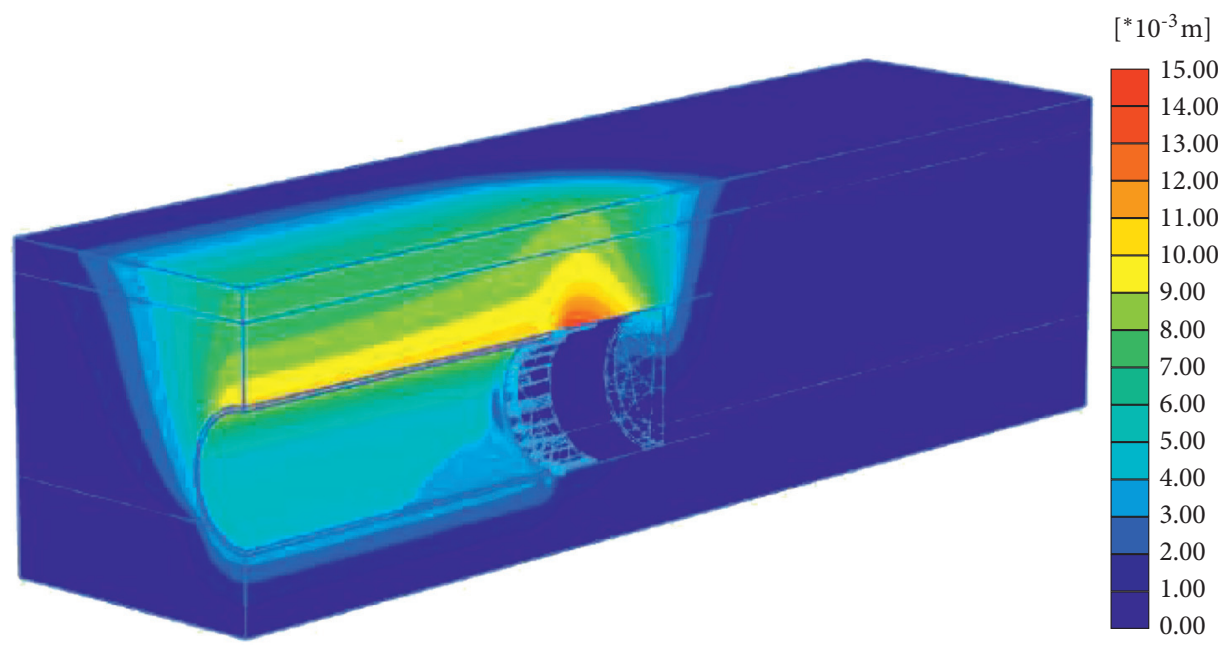

Total displacement $|\mathrm{u}|$

Maximum $=0.00830 \mathrm{~m}$ (Unit 1532 is at node 5873 )

FIgURE 6: Cloud image of ring wall grouting settlement before $-10 \mathrm{~m}$ from section YDK13+001.

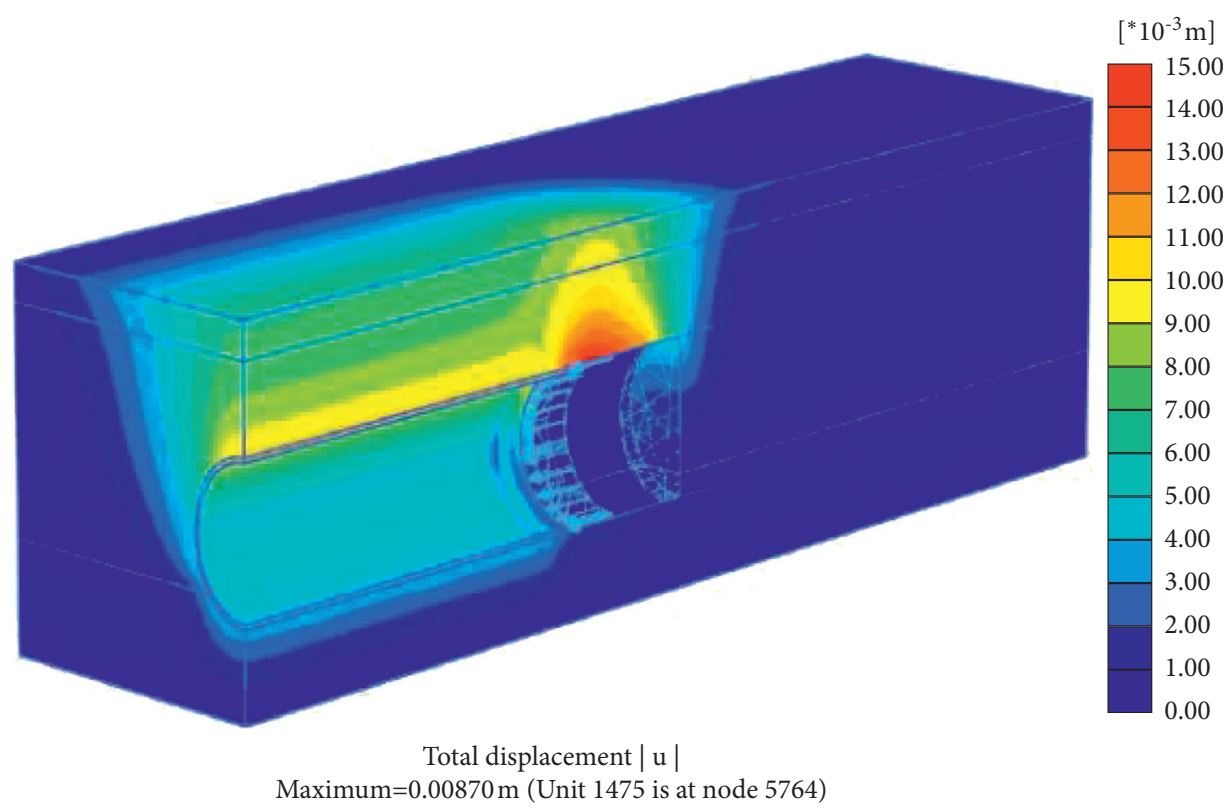

FIGURE 7: Sedimentation cloud map at $-8.5 \mathrm{~m}$ from section YDK13 +001 .

three-layer neural network. The geological conditions and construction parameters of the surrounding rock of the tunnel are used as the input layer, and the evaluation indicators of the dome subsidence, ground settlement, structural force, and the extent of the plastic zone are used as the output layer [16]. Suppose the input neuron is $h$, the hidden layer neuron is $i$, and the output layer neuron is $j$ using $n h, n i$, and $n j$ to denote the number of nodes in the input layer, hidden layer, and output layer, $\theta_{i}$ and $\theta_{j}$ are thresholds of hidden layer node and output layer node, respectively. The input sample is as follows:

$$
\left\{X_{k, h} \mid k=1,2, \ldots, n k ; h=1,2, \ldots, n k ;\right\} .
$$

$$
\left\{d_{k, j} \mid k=1,2, \ldots, n k ; h=1,2, \ldots, n j ;\right\} .
$$

In this evaluation, the median value $n k$ is the number of nodes in the input layer, which is 75 , and the number of nodes in the output layer $n h$ is 14 . The larger the number of hidden layer nodes $n i$, the higher the fitting accuracy of the network, but the lower the generalization ability of the network and the longer the training time. Therefore, under the condition of satisfying accuracy, the value ni should be as small as possible. It is taken as 15 in this assessment.

Functions used:

$$
y=(x-\min )(\max -\min )
$$

The output sample is as follows: 


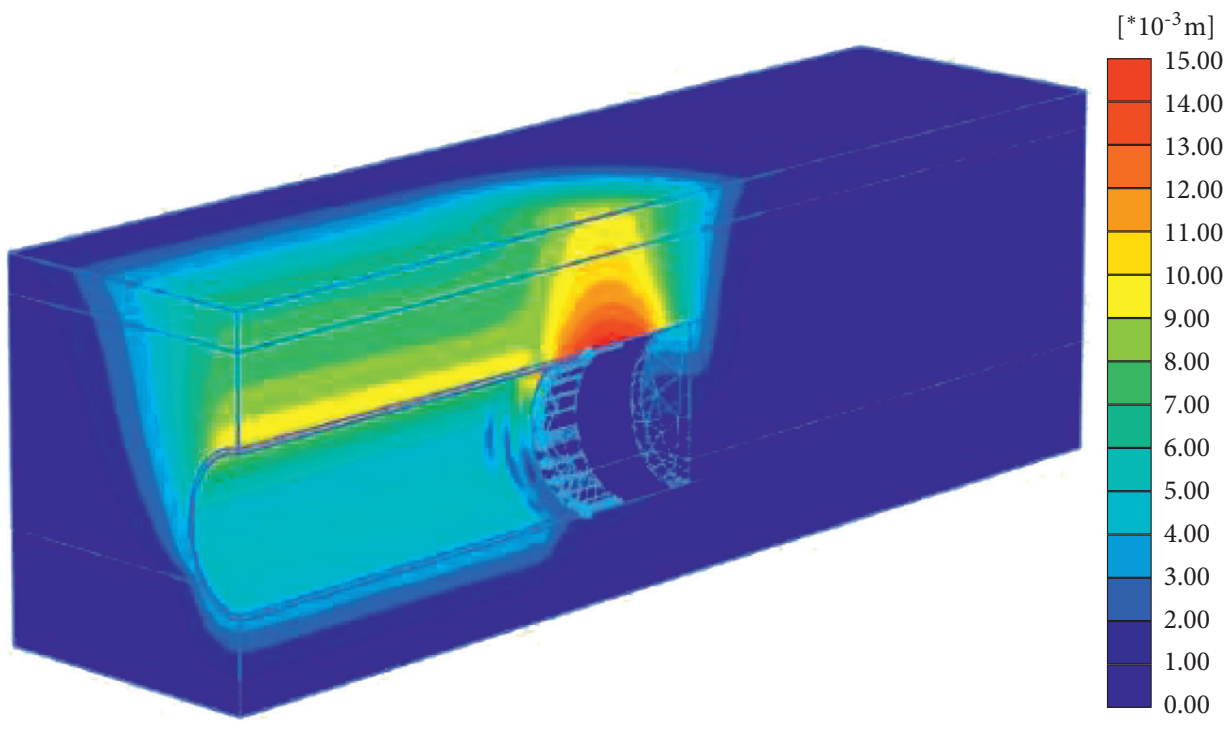

Total displacement $|\mathrm{u}|$

Maximum $=0.00960 \mathrm{~m}$ (Unit 1872 is at node 6549)

FIGURE 8: Settlement cloud diagram at $-6.5 \mathrm{~m}$ from YDK13+001 section.

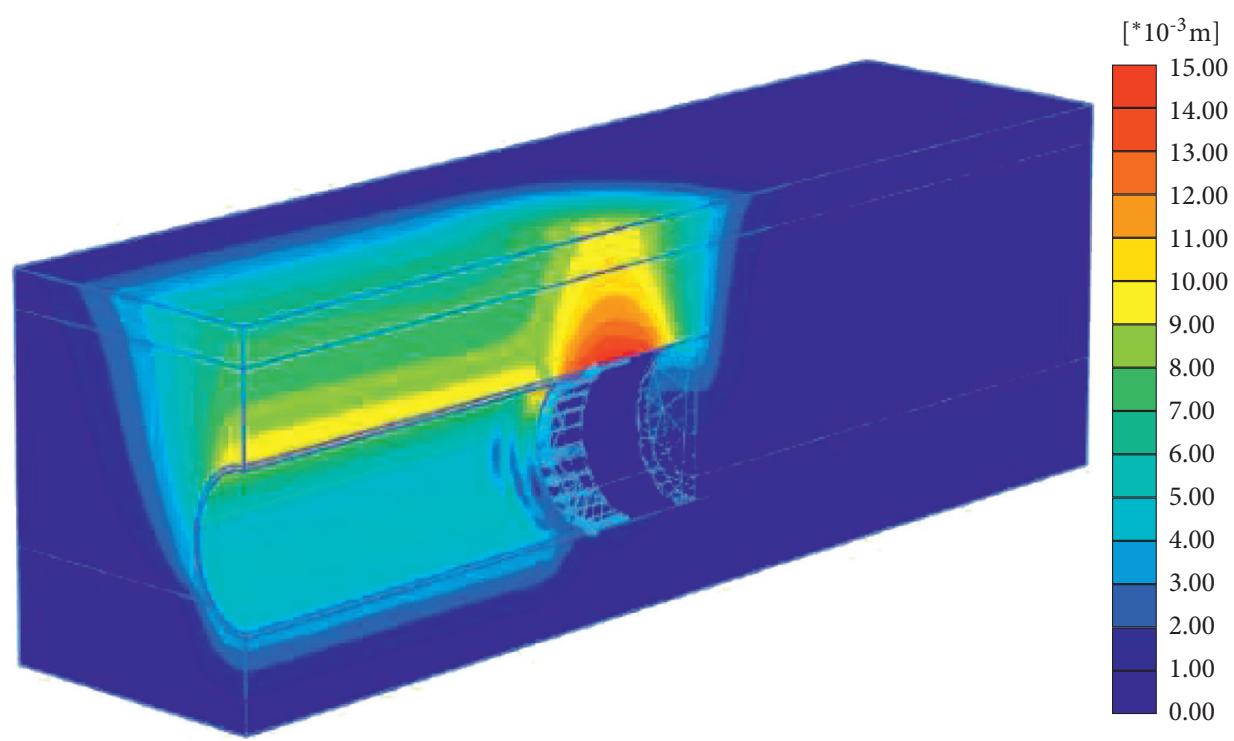

Total displacement $|\mathrm{u}|$

Maximum $=0.00960 \mathrm{~m}$ (Unit 1872 is at node 6549)

FIGURE 9: Deformation cloud image when TBM shield reaches YDK13 + 001 section.

The input and output samples are normalized, where $x$ represents the original data and represents the normalized data. The 1 in the normalization process is processed into 0.99 , and the 0 in the normalization process is processed into 0.11 .

In order to reduce the learning error and make the evaluation result more accurate, the four evaluation indexes of the output layer are trained separately. All the samples corresponding to the four evaluation indicators are learned successively, and their weights and thresholds are obtained. The evaluation result is substituted into the input layer of the artificial neural network model. After calculation, the result of the output layer is the evaluation index value of the current tunnel. The evaluation results are shown in Table 3 .

\section{Responses}

5.1. Management Process Optimization. Based on a large amount of engineering practice experience in the past, combined with many engineering accident lessons, and consulting a large number of literature materials, according to the specific engineering characteristics of Cuobuling 
TABLE 3: The evaluation results.

\begin{tabular}{lc}
\hline Projects & Risk degree (\%) \\
\hline Water burst & 71.21 \\
Surrounding rock deformation & 88.96 \\
Plastic zone & 99.12 \\
Landslide & 83.42 \\
Supporting structure & 82.47 \\
\hline
\end{tabular}

Station, the management process optimization measures are formulated.

5.1.1. Advanced Geological Forecast. The survey of subway tunnel is very difficult. At the same time, due to the equipment and technical reasons, the geological conditions considered in the design are often different from reality [17]. Therefore, it is necessary to use an advanced geological forecast system and geological radar to forecast the geological condition of the tunnel face.

5.1.2. Monitoring Measurement. The tunnel vault subsidence, tunnel circumferential convergence and deformation of the support structure, and water inflow are monitored and measured. According to the disclosed surrounding rock information, a geological sketch of the palm surface is done [18]. The monitoring data and construction information are analyzed in a timely manner and fed back to the technical leader and site supervisor in time.

5.1.3. Dynamic Risk Management. In the process of excavation, a dynamic information management system with the advanced geological forecast, risk assessment, and monitoring measurement as the core should be developed to timely deal with advanced geological forecast results and feed back to the risk assessment system. And the revised construction method should be reassessed according to whether the risk is reduced. The dynamic management diagram is shown in Figure 10.

5.2. Grouting Process Control. Generally speaking, there are two aspects to ensure the effect of field grouting. Firstly, it should strictly control the grouting speed. The filling speed of the slurry should be consistent with the excavation speed of the shield machine as far as possible, so as to minimize the generation of shield tail voids, so as to avoid the settlement caused by shield tail voids. When the grouting speed is too fast, it is necessary to pay attention to the leakage phenomenon of shield tail and damage the construction effect. Therefore, the specific grouting speed should be determined according to the actual construction situation. Secondly, the grouting time is accurately grasped, through the analysis of the above surface subsidence reasons; one of the important reasons for the subsidence is not timely grouting. In the construction of a shield, it is necessary to grasp the timing of grouting. Generally, the best time for grouting is the time when the segment is off the tail of the shield.

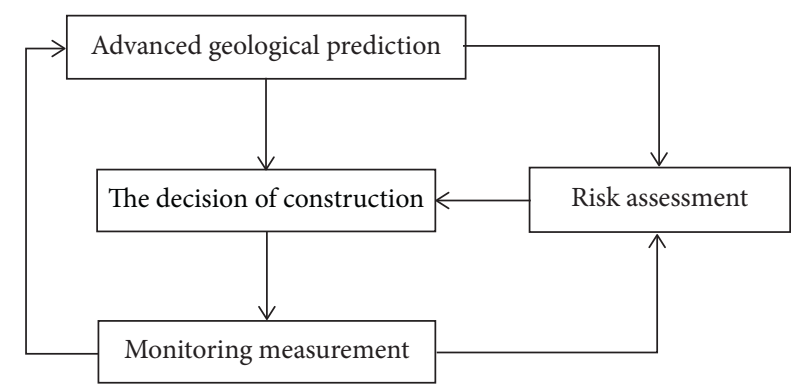

Figure 10: Dynamic management diagram.

5.3. Setting of Heading Parameters. The three parameters of formation earth pressure, groundwater pressure, and preliminary pressure are the earth pressure parameters that need to be controlled during shield construction. Because there are too many factors that cause ground settlement, it is impossible to accurately calculate the specific value of the settlement, so the shield parameters should be adjusted while digging. There are many factors to consider when calculating the earth pressure. The construction of shallow tunnels should follow their respective formulas and make selections based on past experience.

\section{Conclusion}

By increasing the grouting amount, the soil deformation caused by shield construction can be well controlled. The influence range of grouting pressure is $10 \mathrm{M}$ smaller than that of the tail, and it has an obvious effect on reducing the instantaneous settlement of the tail. In addition, in the process of shield propulsion, the influence of shield thrust force and cutter head torque on soil deformation is small, and the change of cutter head torque has no obvious relationship with the change of vertical displacement. The influence of working face pressure is mainly concentrated around the shield incision and has little influence on the shield tail, which is the main factor affecting the soil deformation in front of the shield. It should be pointed out that the soil deformation caused by shield tunneling is a comprehensive expression of the interaction of various influencing factors, and the relationship between vertical displacement and each influencing factor cannot be fully reflected by the relationship between them. According to the measured settlement data and numerical simulation analysis, the influence factors of shield tunnel construction on ground settlement are obtained, which provides a reference for further study of settlement control of shield tunnel construction. In order to deal with settlement caused by metro tunnel construction, the management process should be optimized; grouting technology should be controlled; and tunnel parameters should be set. Taking the ground settlement caused by the shield construction of Cuobuling Station as an example, the field settlement is monitored and analyzed, and the influence of different strata is considered. In the process of tunnel excavation, the shield machine damages the earth pressure balance of the original soil, which leads to the settlement of the top part of the tunnel 
and the cracking of the bottom of the tunnel. PLAXIS 3D software is used to construct the shielding model, and the calculated results are close to the measured data, indicating that the ground subsidence and subsidence trend caused by the shielding constant can be accurately predicted by using PLAXIS 3D software for finite element analysis.

\section{Data Availability}

The experimental data used to support the findings of this study are available from the corresponding author upon request.

\section{Conflicts of Interest}

The authors declare that they have no conflicts of interest regarding this work.

\section{References}

[1] R. L. Sousa and H. H. Einstein, "Risk analysis during tunnel construction using Bayesian Networks: Porto Metro case study," Tunnelling and Underground Space Technology incorporating Trenchless Technology Research, vol. 27, no. 1, pp. 86-100, 2011.

[2] G. Atzl, G. Ullmann, and M. Schmidt, "Planning of tunnel excavation for the Vienna underground - construction Lot U1/9/Planung der Tunnelvortriebe für die Wiener U-Bahn b," Geomechanics and Tunnelling, vol. 8, no. 1, pp. 74-82, 2015.

[3] Z. Zhao, "Study on differential grey neural net-AR model based on wavelet decomposition and its application in subway tunnel settlement prediction," Bulletin of Surveying and Mapping, vol. 34, no. 1, pp. 104-108, 2020.

[4] K. Pan, L. Tian, and C. Li, "Analysis on the prediction effect of dynamic grey time-series neural network combined model in subway operation period," Site Investigation Science and Technology, vol. 100, no. 2, pp. 49-52, 2019.

[5] Y.-H. Kim, "Progress in civil, architectural and hydraulic engineering IV," American Journal of Anatomy, vol. 10, no. 1201, pp. 123-131, 2015.

[6] X. Liu and F. Sun, "Comparison and selection of tunnel construction schemes based on numerical simulation," Journal of Civil Engineering and Management, vol. 35, no. 3, pp. 1-6, 2018.

[7] C. Di Perna, A. Carbonari, R. Ansuini, and M. Casals, "Empirical approach for real-time estimation of air flow rates in a subway station," Tunnelling and Underground Space Technology, vol. 42, no. 5, pp. 25-39, 2014.

[8] H. Liu and D. Wang, "Study on subsidence change law of underground tunnel underpass existing buildings," Research on Urban Rail Transit, vol. 22, no. 6, pp. 47-51, 2019.

[9] A. Scheller, "The second S-Bahn trunk line in Munich/Die zweite S-Bahn-Stammstrecke München," Geomechanics and Tunnelling, vol. 8, no. 2, pp. 115-128, 2015.

[10] G. Papastamos, S. Stiros, V. Saltogianni, and V. Kontogianni, "3-D strong tilting observed in tall, isolated brick chimneys during the excavation of the Athens Metro," Applied Geomatics, vol. 7, no. 2, pp. 1-7, 2014.

[11] A. L. Costa, R. L. Sousa, and H. H. Einstein, "Probabilistic 3D alignment optimization of underground transport infrastructure integrating GIS-based subsurface characterization,"
Tunnelling and Underground Space Technology, vol. 72, no. 2, pp. 233-241, 2017.

[12] K. Rabensteiner and S. Notarianni, "Cityringen - extension of the Copenhagen metro/Cityringen - Ausbau der Metro Kopenhagen," Geomechanics and Tunnelling, vol. 6, no. 5, pp. 542-550, 2013.

[13] S. Chen, T. Ren, and P. Deng, "Tunnel settlement prediction based on artificial bee colony optimization wavelet neural network," Modern Tunneling Technology, vol. 52, no. 4, pp. 56-61, 2019.

[14] P. Qi, "Analysis and study on the influence of additional load on the construction of transfer structure foundation of upper cross metro tunnel," Modern Tunneling Technology, vol. 390, no. 1, pp. 105-110, 2020.

[15] H. Chakeri, Y. Ozcelik, and B. Unver, "Investigation of ground surface settlement in twin tunnels driven with EPBM in urban area," Arabian Journal of Geosciences, vol. 8, no. 9, pp. 7655-7666, 2015.

[16] S. Kim and J. Heo, "Development of 3D underground cadastral data model in Korea: based on land administration domain model," Land Use Policy, vol. 60, pp. 123-138, 2017.

[17] X. Wang, H. Jiang, and K. Zhu, "Ground subsidence law of urban metro tunnel construction process based on earth pressure shield," Earth Science, vol. 44, no. 12, pp. 4293-4298, 2019.

[18] B. D. Doelder, R. Berkelaar, C. Luijten, and V. Thumann, "Practical integration of risk management and monitoring during rebuilding of subway station CS Rotterdam," Iabse Symposium Report, vol. 99, no. 3, pp. 606-607, 2013. 